\title{
Bazı Pelemir (Cephalaria syriaca L.) Genotiplerinin Türkiye’nin Farklı Ekolojik Koşullarında Verim ve Kalite Değerlerinin Belirlenmesi
}

\author{
Dr. Mehmet SEZGIN ${ }^{1}$ Hatice TEZCAN ${ }^{1} \quad$ Mehmet ŞAHIN $^{1}$ Dr. Yusuf ARSLAN ${ }^{2}$ İlhan SUBAȘI ${ }^{3}$ \\ İsmail DEMIR ${ }^{4}$ Dr. Hasan KOÇ
}

\author{
${ }^{1}$ Tohumluk Tescil ve Sertifikasyon Merkez Müdürlüğü/Ankara \\ ${ }^{2}$ Tarımsal Araştırmalar ve Politikalar Genel Müdürlüğü/Ankara \\ ${ }^{3}$ Tarla Bitkileri Merkez Araştırma Enstitüsü Müdürlüğü/Ankara \\ ${ }^{4}$ Ahi Evren Üniversitesi Ziraat Fakültesi Tarla Bitkileri Bölümü/Kırşehir \\ ${ }^{5}$ Bahri Dağdaş Uluslararası Tarımsal Araştırma Enstitüsü Müdürlüğü/Konya \\ $\triangle:$ msezgin40@hotmail.com
}

Geliş (Received): 03.11.2017

Kabul (Accepted): 15.12.2017

\begin{abstract}
ÖZET: Bu çalışma 2015-2016 yıllarında, bazı pelemir genotiplerinin (Karahan, Populasyon-1 ve Populasyon-2) Ankara (Yenimahalle), Ankara (Yenikent), Ankara (Haymana), Konya ve Kırşehir ekolojilerindeki tane verimi ve kalite değerlerinin saptanması amacıyla, tesadüf blokları deneme deseninde 6 tekrarlamalı olarak yürütülmüştür. İki yıllık ortalama sonuçlarına göre tane verimleri $41.1-233.2 \mathrm{~kg} \mathrm{da}^{-1}$, yă̆ oranları $\% 20.2-26.2$ ve yağ verimleri 10.3 - $58.9 \mathrm{~kg} \mathrm{da}^{-1}$ arasında değiştiği belirlenmiştir. Bu çalışma sonucunda en düşük ortalama tane verimi $52.4 \mathrm{~kg} \mathrm{da}^{-1} \mathrm{ile}$ Ankara (Yenikent -2015) lokasyonu, en yüksek tane verimini ise $250.9 \mathrm{~kg}$ da-1 ile Ankara (Haymana - 2015) lokasyonunda alınmıştır. Karahan genotipi ortalama $233.2 \mathrm{~kg} \mathrm{da}^{-1}$ tane verimi ve $58.9 \mathrm{~kg} \mathrm{da}^{-1}$ yağ verimi ile öne çıkarken, Populasyon-1 genotipi ise ortalama \% 26.2 ile en yüksek yă̆ oranı değerini göstermiştir.
\end{abstract}

Anahtar Kelimeler: Pelemir, tane verimi, yağ oranı, yağ verimi

\section{Determination of Yield and Quality Values of Some Type Cephalaria syriaca L Cultivated in Different Ecological Conditions in Turkey}

ABSTRACT: The aim of this study is to determine the grain yield and the quality values of Karahan, Population -1 and Population-2 some type Cephalaria syriaca L. genotypes in Ankara (Center), Ankara (Yenikent), Ankara (Haymana), Konya and Kırşehir ecological conditions in 2015-2016, conducted with random block design and in 6 replications. According to two years average results; grain yield ranged from $41.1-233.2 \mathrm{~kg}$ da-1, oil ratio ranged from $20.2 \%-26.2$ and oil yield ranged from $10.3-58.9 \mathrm{~kg}$ da-1. As a result of this study, the lowest average yield was in Ankara (Yenikent -2015) location with $52.4 \mathrm{~kg}$ da-1 and highest grain yield is obtained from Ankara (Haymana - 2015) location with $250.9 \mathrm{~kg}$ da-1. The Karahan genotype came forward with average grain yield of $233.2 \mathrm{~kg}$ da-1 and $58.9 \mathrm{~kg}$ da-1 oil yield, Population-1 genotype showed highest oil content with the average value of $26.2 \%$.

Keywords : Cephalaria, grain yield, oil content - oil rate, oil yield

\section{GíRiș}

Ülkemizde, ayçiçeği, soya, yerfistığı, susam, kolza, pamuk, haşhaş, aspir, keten ve kenevir gibi yağlı tohumlu bitkilerin üretimleri başarıyla yapılabilmektedir. Ülkemizdeki yă üretimini artırabilmek için bir taraftan, bu bitkilerin ekim alanlarının genişletilip, verimlilikleri artırılırken diğer taraftan alternatif olabilecek yağlı tohumlu bitkiler üzerinde çalışmaların yapılması gerekmektedir (Arıoğlu ve ark., 2010). Bu açıdan bakıldığında kış soğuklarına olan dayanıklılığıyla ve verimsiz topraklarda bile tarımının yapılabilmesiyle pelemir bitkisi dikkat çekmektedir.

Pelemir (Cephalaria syriaca L.), Dipsacaceae familyasında yer alan, Anadolu'da büyük yaygınlık gösteren, buğday tarlalarında yabani olarak yetişen ve yetişme formu buğdaya benzemese de tane yapısı, boyu ve şekil bakımından oldukça benzeyen bir bitkidir (Boz ve Karaoğlu, 2013). Cephalaria'nın 1940‘a kadar dünya genelinde toplam 65 türü belirlenmişken, günümüzde bu sayının yaklaşık 94'e yükseldiği yapılan çalışmalarda ortaya çıkmıştır. Pelemir dünyada en çok Akdeniz Bölgesi'nde ve Batı Asya'da bulunmaktadır. Diğer ülkelerle kıyaslandığında ise en çok Türkiye, Güney Fransa, Güney İspanya ve Kuzey Afrika'da bulunmaktadır (Çiller, 1977).

Soğuğa oldukça dayanıklı olan pelemir bitkisinin fazla bir iklim isteği bulunmamaktadır. Killi ve tınlı topraklarda çok iyi yetişmektedir. Fakat toprak derinliği fazla olmayan eğimli ve erozyona maruz olan marjinal alanlarda bile yetiştirilebilmekte ve bu topraklar için tatmin edici düzeyde verim alınabilmektedir (Çiller, 1977).

Ülkemizde1970'li yıllara kadar, bitkinin tohumlarındaki yağ oranın \% 21-26 düzeyinde olması pelemirin yağ bitkisi olarak kullanılmasına neden olmuştur (Baytop, 1999). Pelemir yağı yeşilimsi sarı renkte olup, hoş kokuludur. Bu yağ doğrudan yemeklik olarak kullanılabildiği gibi diğer yağlarla karıștırılarak da kullanılmıştır. Fakat pelemir yağında bulunan \% 7-8 dolayındaki epoksi asit bu yağın bu haliyle yemeklik olarak kullanılmaması gerektiğini göstermektedir. 
Pelemir yağı içerdiği \% 19-20 oranındaki miristik asit nedeniyle sabun sanayi için oldukça elverişlidir (Yazicioğlu ve ark., 1978). Diğer taraftan içerdiği epoksi asit nedeniyle deri ve tekstil sanayinde kullanılması uygundur. Yağda linoleik, miristik, oleik ve palmitik asit içeriği yüksek olmasına rağmen linolenik ve stearik asit oranı düşüktür, erüsik asit ise bulunmamaktadır (Yazıcıoğlu ve Karaali, 1983; Hallen ve ark., 2004; Karaoğlu, 2012). Ayrıca yağı çıarıldıktan sonra arta kalan küspesi de hayvan beslemede kullanılabilecek bir kesif yem kaynağıdır (Çiller, 1977).

Pelemir, özellikle ekmek yapımı için düşük kaliteye sahip buğdaylardan elde edilen unlarda hamuru kuvvetlendirmek, daha stabil bir yapı yakalamak amacıyla ülkemizde geleneksel olarak kullanılan doğal bir katkıdır. Çok düşük düzeylerde bile yüksek verimde etki gösterdiği belirtilen pelemirin firın ürünlerinin kalite özelliklerine olumlu yönde etki ettiği, tazeliğini en az birkaç gün koruduğu ifade edilmektedir (Altuniğne ve Saygın, 1985). Pelemir tohumu besince zengin olup \% 22-28 yağ, \% 14-21 protein, \% 3-10 kül ve \% 9-30 ham lif oranına sahiptir. Pelemir tohumlarından elde edilen un ve yağ düşük düzeylerde (\% $\quad$ 0.5-3.0) buğday ununa karıştırılarak ekmeğin bayatlamasını geciktirmekte ve hamurun daha iyi kabarmasında faydalanılmaktadır (Karaoğlu, 2006). Pelemir, özellikle ülkemizde kırsal kesimlerde yaşayan insanlar tarafindan ekmek yapımında, zayıf hamurların kuvvetlendirilmesinde geleneksel olarak kullanılmakta, bu yüzden buğday tarlalarında yetişmesine izin verilmektedir (Boz ve Karaoğlu, 2013). Başar ve ark. (2016)'nn bildirdiğine göre, \% 15 süne zararı olan un örneklerine pelemir unu ilavesi, yoğurma toleransı ve yumuşama derecesini düşürmüştür.

Çalışmamızda, kışlık olarak ekilen pelemir bitkisinin farklı lokasyonlarda tane verimi, yağ verimi ve yağ oranları belirlemek amacıyla planlanmış ve yürütülmüşütür.

\section{MATERYAL}

Bu araştırmada materyal olarak kullanılan pelemir (Cephalaria syriaca L.) genotipleri Kayseri ilinin Felahiye ilçesine bağlı İsabey Köyünden Tarla Bitkileri Merkez Araştırma Müdürlüğü tarafından toplanmıştır. Bu araştırmada Tarla Bitkileri Merkez Araştırma Enstitüsü Müdürlüğü tarafından temin edilen 3 adet pelemir genotipi kullanılmışıı. Denemelerde yer alan geneotip isimleri ve genotip sahibi kuruluşlar Çizelge $1^{\prime}$ de verilmiştir.

Çizelge 1.Denemelerde yer alan geneotipler ve genotip sahibi kuruluşlar

\begin{tabular}{|l|l|}
\hline Geneotipler & Genotip sahibi kuruluşlar \\
\hline 1-Karahan & Tarla Bitkileri Merkez Araştırma Enstitüsü Müdürlüğg̈//Ankara \\
\hline 2-Populasyon1 & Tarla Bitkileri Merkez Araştırma Enstitüsü Müdürlüğ̈/Ankara \\
\hline 3-Populasyon2 & Tarla Bitkileri Merkez Araştırma Enstitüsü Müdürlüğ̈̈/Ankara \\
\hline
\end{tabular}

\section{METOT}

Bu çalışma, 2014-2015 ve 2015-2016 kışlık ekim dönemlerinde 2 yıllık bir çalışma olarak Tarla Bitkileri Merkez Araştırma Enstitüsü Müdürlüğünün Ankara (Haymana) ve Ankara (Yenimahalle), Tohumluk Tescil ve Sertifikasyon Merkez Müdürlüğünün Ankara (Yenikent), Ahi Evren Üniversitesi Ziraat Fakültesi Tarla Bitkileri Bölümünün Kırşehir, Bahri Dağdaş Uluslararası Tarımsal Araştırma Enstitüsü Müdürlüğünün Konyadaki deneme tarlalarında yürütülmüştür. Ankara'da (Haymana) 10.10.2014 ve 21.10.215, Ankara'da (Yenimahalle) 17.10.2014 ve 05.11.2015, Ankara'da (Yenikent) 05.11.2014 ve 19.10.2015, Konya'da 13.10.2014 ve 16.10.2015, Kırşehir'de ise 13.10.2014 tarihlerinde kışlık olarak ekilmiştir. Deneme Tesadüf Blokları Deneme desenine göre altı tekerrürlü olarak kurulmuştur. Parsel boyutları sıra arasi $25 \mathrm{~cm}$, sıra üzeri $10 \mathrm{~cm}$, parsel uzunluğu $5 \mathrm{~m}$, parselde 5 sıra olarak alınmıştır. Toplam parsel alanı $1.25 \mathrm{~m} \times 5 \mathrm{~m}=6.25 \mathrm{~m}^{2}$ dir. Çıkıştan sonra bitkiler sıra üzeri $10 \mathrm{~cm}$ olacak şekilde seyreltilmiştir. Denemede herhangi bir gübreleme yapılmamıştır. Tohum verimleri her bir parselde kenardaki birer sira atıldıktan ve parsellerin her iki ucundan 0.5 'er m kenar tesiri olarak çıkıldıktan sonra geri kalan bitkiler üzerinden hesaplanmıştır. Yağ oranları ise Tarla Bitkileri Merkez Araştırma Enstitüsü Müdürlüğü ve Ahi Evren
Üniversitesi Ziraat Fakültesi Tarla Bitkileri Bölümü'nde yaptırılan analizle belirlenmiştir. Dekara yağ verimleri ise dekara tohum verimi ve yağ oranları üzerinden hesaplanmıştır.

Araştırma sonunda elde edilen veriler Tesadüf Blokları Deneme Desenine göre varyans analizi yapılmıştır. Uygulamalar arasındaki farklılıkların önem düzeylerini belirleyebilmek amaciyla Duncan Testi kullanılmıştır (Düzgünes ve ark. 1987). Tüm istatistikî hesaplamalar bilgisayarda SAS 9 paket programı kullanılarak tane verimi ve yağ verimi bakımından çeşitler arasındaki farkın önemlilik dereceleri belirlenmiştir.

\section{BULGULAR ve TARTIŞMA}

\section{Tane Verimi (kg/da)}

2014-2015 ve 2015-2016 kışlık ekim yetiştirme döneminde Ankara (Haymana), Ankara (Yenikent), Ankara (Merkez), Kırşehir ve Konya illerindeki lokasyonlarda 3 farklı genotiple 5 farklı lokasyonda kurulan bu denemelerden elde edilen veriler her iki y1l istatistiki analize tabi tutularak tane ve yağ verimleri bakımından genotipler arasındaki farkın istatistiki önemlilik dereceleri belirlenmiştir. Her iki yılda da tane ve yağ verimi yönünden genotipler, lokasyonlar ve yıllar arasındaki fark \% 1 düzeyinde önemli bulunmuştur. 2014-2015 yetiştirme döneminde, 
lokasyonların ortalama tane verimleri 52.4-250.9 $\mathrm{kg} \mathrm{da}^{-1}$ arasında olmuş, en yüksek tane verimi Ankara (Haymana) lokasyonundan elde edilmiştir. Genotiplerin ortalama tane verimleride $43.7-247.1 \mathrm{~kg} \mathrm{da}^{-1}$ arasinda olmuş ve en yüksek tane verimini Populasyon 2 genotipi göstermiştir 2015-2016 yetiştirme döneminde ise, lokasyonların ortalama tane verimleri $115.6-176.4 \mathrm{~kg}$ $\mathrm{da}^{-1}$ arasında olmuş, en yüksek tane verimi Ankara (Yenimahalle) lokasyonundan elde edilmiştir. Genotiplerin ortalama tane verimleride $37.9-225.2 \mathrm{~kg}$ $\mathrm{da}^{-1}$ arasında değişmiş ve en yüksek tane verimini Karahan genotipi göstermiştir. Yıl ve lokasyonlara göre ortalama tane verimleri $41.1-233.2 \mathrm{~kg} \mathrm{da}^{-1}$ arasinda değişim gösterirken, en yüksek tane verimi Karahan genotipinden elde edilmiştir. Yetiştirme dönemleri arasından en yüksek tane verimi $176.8 \mathrm{~kg} \mathrm{da}^{-1}$ ile 20142015 yetiştirme döneminde alınmıştır. İki yılın genel ortalaması olarak tane verimi $163.7 \mathrm{~kg} \mathrm{da}^{-1}$ bulunmuştur (Çizelge 2).

Tohum verimine ait 41.1-233.2 $\mathrm{kg} \mathrm{da}^{-1}$ değer Çiller (1977), Çağlar (1968) ve Katar ve ark. (2012) 'nın bildirdiği değerlerden yüksek çıkmıştır. Arslan ve ark.(2012) ile uyumluluk göstermiş̧tir.

Yağ Oranı (\%)

2014-2015 yetiştirme döneminde, lokasyonların ortalama yağ oranları \% 23.9-24.7 arasında olmuş, en yüksek yağ oranı Ankara (Yenimahalle) lokasyonundan elde edilmiştir. Genotiplerin ortalama yă oranları \% 20.7-28.0 arasında olmuş ve en yüksek yağ oranını Populasyon 1 genotipi göstermiştir. 2015-2016 yetiştirme döneminde ise, lokasyonların ortalama yăg oranları \% 21.5-23.0 arasında olmuş, en yüksek yăg oranı Ankara (Haymana) lokasyonundan elde edilmiştir.

Çizelge 2. Bazı Pelemir genotiplerinin 2014-2015 ve 2015-2016 kışlık ekim yetiştirme dönemlerine ait tane verim sonuçları $\left(\mathrm{kg} \mathrm{da}^{-1}\right)$

\begin{tabular}{|c|c|c|c|c|c|c|c|c|c|c|c|c|}
\hline \multirow[b]{2}{*}{ Genotipler } & \multicolumn{6}{|c|}{2014 - 2015 kışlık ekim yetiştirme dönemi } & \multicolumn{5}{|c|}{2015 - 2016 kışlık ekim yetiştirme dönemi } & \multirow[b]{2}{*}{ 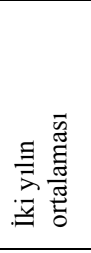 } \\
\hline & 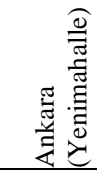 & 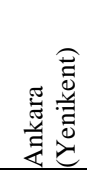 & 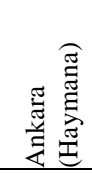 & 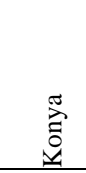 & 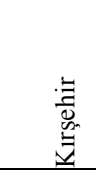 & 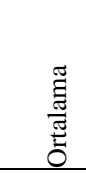 & 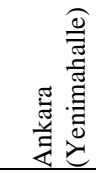 & 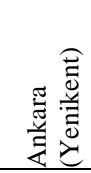 & 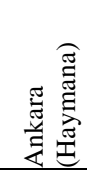 & 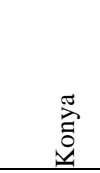 & $\begin{array}{l}\stackrel{\Xi}{\Xi} \\
\frac{\pi}{\pi} \\
0\end{array}$ & \\
\hline Karahan & $261.1 \mathrm{a}$ & $\begin{array}{l}86.2 \\
\mathrm{a}\end{array}$ & $\begin{array}{l}400.0 \\
\mathrm{a}\end{array}$ & $\begin{array}{l}230.4 \\
b\end{array}$ & $220.6 \mathrm{~b}$ & $\begin{array}{l}239.7 \\
\mathrm{a}\end{array}$ & $\begin{array}{l}256.6 \\
a\end{array}$ & $\begin{array}{l}196.7 \\
\mathrm{a}\end{array}$ & $\begin{array}{l}268.6 \\
a\end{array}$ & $178.8 \mathrm{a}$ & $225.2 \mathrm{a}$ & $233.2 \mathrm{a}$ \\
\hline $\begin{array}{l}\text { Populasyon-1 } \\
\text { (st) }\end{array}$ & $29.9 \mathrm{~b}$ & $\begin{array}{l}29.2 \\
\mathrm{c}\end{array}$ & $\begin{array}{l}47.5 \\
\mathrm{c}\end{array}$ & $40.9 \mathrm{c}$ & $71.0 \mathrm{c}$ & $43.7 \mathrm{~b}$ & $34.0 \mathrm{~b}$ & $52.9 \mathrm{c}$ & $\begin{array}{l}26.0 \\
\mathrm{c}\end{array}$ & $38.6 \mathrm{~b}$ & $37.9 \mathrm{c}$ & $41.1 \mathrm{c}$ \\
\hline $\begin{array}{l}\text { Populasyon-2 } \\
\text { (st) }\end{array}$ & $258.3 \mathrm{a}$ & $\begin{array}{l}11.8 \\
\mathrm{~b}\end{array}$ & $\begin{array}{l}305.2 \\
\mathrm{~b}\end{array}$ & $\begin{array}{l}322.0 \\
\mathrm{a}\end{array}$ & $307.9 \mathrm{a}$ & $\begin{array}{l}247.1 \\
\mathrm{a}\end{array}$ & $\begin{array}{l}238.5 \\
\mathrm{a}\end{array}$ & $97.3 \mathrm{~b}$ & $\begin{array}{l}229.2 \\
\mathrm{~b}\end{array}$ & $152.2 \mathrm{a}$ & $179.3 \mathrm{~b}$ & $216.9 \mathrm{~b}$ \\
\hline $\mathrm{F}$ & $* *$ & $* *$ & $* *$ & $* *$ & $* *$ & $* *$ & $* *$ & $* *$ & $* *$ & $* *$ & $* *$ & $* *$ \\
\hline$\% \mathrm{CV}$ & 10.3 & 16.7 & 13.8 & 19.3 & 15.7 & 16.2 & 9.1 & 12.0 & 10.9 & 18.2 & 12.3 & 15.0 \\
\hline LSD & 24.2 & 11.2 & 44.6 & 49.2 & 40.4 & 14.8 & 20.6 & 17.8 & 24.4 & 28.8 & 10.6 & 9.4 \\
\hline $\begin{array}{l}\text { Lokasyon } \\
\text { Ortalaması }\end{array}$ & $183.1 \mathrm{~b}$ & $\begin{array}{l}52.4 \\
\mathrm{c} \\
\end{array}$ & $\begin{array}{l}250.9 \\
\mathrm{a}\end{array}$ & $\begin{array}{l}197.8 \\
b\end{array}$ & $\begin{array}{l}199.8 \\
b^{* *}\end{array}$ & $\begin{array}{l}176.8 \\
\mathrm{a} \\
\end{array}$ & $\begin{array}{l}176.4 \\
\mathrm{a}\end{array}$ & $\begin{array}{l}115.6 \\
b\end{array}$ & $\begin{array}{l}174.6 \\
\mathrm{a}\end{array}$ & $\begin{array}{l}123.2 \\
b^{* *}\end{array}$ & $\begin{array}{l}147.4 \\
b^{* *}\end{array}$ & 163.7 \\
\hline
\end{tabular}

(*) \%5 düzeyinde önemli $\quad(* *) \% 1$ düzeyinde önemli

Çizelge 3. Bazı Pelemir genotiplerinin 2014-2015 ve 2015-2016 kışlık ekim yetiştirme dönemlerine ait yağ oranları $(\%)$ ve yă verimleri $\left(\mathrm{kg} \mathrm{da}^{-1}\right)$

\begin{tabular}{|c|c|c|c|c|c|c|c|c|c|c|c|c|c|c|}
\hline & \multicolumn{7}{|c|}{ Yağ oranı $(\%)$} & \multicolumn{7}{|c|}{ Yağ verimi $\left(\mathrm{kg} \mathrm{da}^{-1}\right)$} \\
\hline & \multicolumn{3}{|c|}{$\begin{array}{c}2014-2015 \\
\text { kışlık ekim } \\
\text { yetiştirme dönemi } \\
\end{array}$} & \multicolumn{3}{|c|}{$\begin{array}{c}2015-2016 \\
\text { kışlık ekim yetiştirme } \\
\text { dönemi }\end{array}$} & \multirow[b]{2}{*}{ 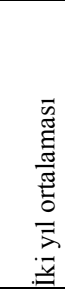 } & \multicolumn{3}{|c|}{$\begin{array}{c}2014-2015 \\
\text { kışlık ekim yetiştirme } \\
\text { dönemi } \\
\end{array}$} & \multicolumn{3}{|c|}{$\begin{array}{c}2015-2016 \\
\text { kışlık ekim yetiştirme } \\
\text { dönemi }\end{array}$} & \multirow{2}{*}{ 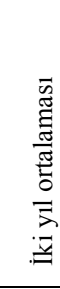 } \\
\hline & 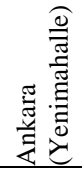 & 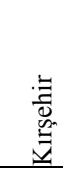 & 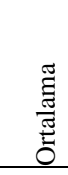 & 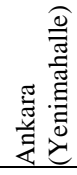 & 胥 & 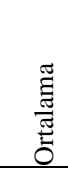 & & 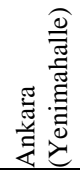 & 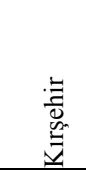 & 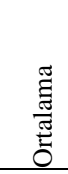 & 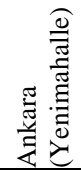 & 㞼 & 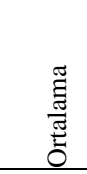 & \\
\hline Karahan & 24.5 & 23.9 & 24.2 & 20.8 & 24.3 & 22.6 & 23.4 & $\begin{array}{l}64.0 \\
\mathrm{a}\end{array}$ & $52.6 \mathrm{~b}$ & $\begin{array}{l}58.3 \\
\mathrm{a} \\
\end{array}$ & $\begin{array}{l}53.4 \\
\mathrm{a} \\
\end{array}$ & $65.3 \mathrm{a}$ & $59.3 \mathrm{a}$ & $\begin{array}{l}58.8 \\
\mathrm{a}\end{array}$ \\
\hline $\begin{array}{l}\text { Populasyon-1 } \\
\text { (st) }\end{array}$ & 31.6 & 24.3 & 28.0 & 24.7 & 24.1 & 24.4 & 26.2 & $9.4 \mathrm{c}$ & $17.3 \mathrm{c}$ & $\begin{array}{l}13.4 \\
b\end{array}$ & $8.4 \mathrm{c}$ & $6.3 \mathrm{c}$ & $7.3 \mathrm{c}$ & $\begin{array}{l}10.3 \\
\mathrm{c}\end{array}$ \\
\hline $\begin{array}{l}\text { Populasyon-2 } \\
\text { (st) }\end{array}$ & 18.0 & 23.4 & 20.7 & 19.0 & 20.6 & 19.8 & 20.2 & $\begin{array}{l}46.5 \\
b\end{array}$ & $72.2 \mathrm{a}$ & $\begin{array}{l}59.3 \\
\mathrm{a}\end{array}$ & $\begin{array}{l}45.3 \\
b\end{array}$ & $47.2 \mathrm{~b}$ & $46.3 \mathrm{~b}$ & $\begin{array}{l}52.8 \\
b\end{array}$ \\
\hline $\mathrm{F}$ & & & & & & & & $* *$ & $* *$ & $* *$ & $* *$ & $* *$ & $* *$ & $* *$ \\
\hline$\% \mathrm{CV}$ & & & & & & & & 10.6 & 16.4 & 14.3 & 13.7 & 13.9 & 13.8 & 14.1 \\
\hline LSD & & & & & & & & 5.5 & 10.0 & 5.3 & 6.3 & 7.1 & 4.4 & 3.4 \\
\hline $\begin{array}{l}\text { Lokasyon } \\
\text { Ortalaması }\end{array}$ & 24.7 & 23.9 & 24.3 & 21.5 & 23.0 & 22.3 & 23.3 & $\begin{array}{l}40.0 \\
b\end{array}$ & $\begin{array}{l}47.4 \\
a^{* *}\end{array}$ & $\begin{array}{l}43.7 \\
\mathrm{a}\end{array}$ & $\begin{array}{l}35.7 \\
b\end{array}$ & $\begin{array}{l}39.6 \\
a^{* *}\end{array}$ & $\begin{array}{l}37.6 \\
b^{* *}\end{array}$ & 40.6 \\
\hline
\end{tabular}

(*) \%5 düzeyinde önemli $\quad(* *) \% 1$ düzeyinde önemli 
Genotiplerin ortalama yă oranları \% $19.8-24.4$ arasında olmuş ve en yüksek yağ oranını Populasyon 1 genotipi göstermiştir. Y1l ve lokasyonlara göre ortalama yă̆ oranları \% 20.2-26.2 arasında değişim gösterirken, en yüksek ortalama yağ oranı Populasyon 1 genotipinden elde edilmiştir. Yetiştirme dönemleri arasından en yüksek ortalama yă oranı \% 24.3 ile 2014-2015 yetiştirme döneminde alınmıştır. İki yılın genel ortalaması olarak yağ oranı \% 23.3 bulunmuştur (Çizelge 3). Yağ oranına ait \% 20.2-26.2 değer, Arslan ve ark.(2012), Katar ve ark.(2012), Çiller (1977), Yazıcıoğlu et al. (1978) ve Çağlar (1968)'ın Kayseri, Avanos ve Yozgat yöreleri için bildirdiği değerler ile uyumluluk göstermiştir.

Yă̆ Verimi (kg da $\left.{ }^{-1}\right)$

2014-2015 yetiştirme döneminde, lokasyonların ortalama yă verimleri $40.0-47.4 \mathrm{~kg} \mathrm{da}{ }^{-1}$ arasında olmuş, en yüksek yağ verimi Ankara (Yenimahalle) lokasyonundan elde edilmiştir. Genotiplerin ortalama yă verimleride 13.4-59.3 $\mathrm{kg} \mathrm{da}^{-1}$ arasında olmuş ve en yüksek yağ verimini Populasyon 2 genotipi göstermiştir 2015-2016 yetiştirme döneminde ise, lokasyonların ortalama yağ verimleri $35.7-39.6 \mathrm{~kg} \mathrm{da}{ }^{-1}$ arasında olmuş, en yüksek yağ verimi Ankara (Haymana) lokasyonundan elde edilmiştir. Genotiplerin ortalama yağ verimleride 7.3-59.3 $\mathrm{kg} \mathrm{da}^{-1}$ arasında olmuş ve en yüksek yağ verimini Karahan genotipi göstermiştir. Y11 ve lokasyonlara göre ortalama yağ verimleri 10.3-58.8 $\mathrm{kg} \mathrm{da}{ }^{-1}$ arasında değişim gösterirken, en yüksek yağ verimi Karahan genotipinden elde edilmiştir. Yetiştirme dönemleri arasından en yüksek yağ verimi $43.7 \mathrm{~kg} \mathrm{da}^{-1}$ ile 2014-2015 yetiştirme döneminde alınmıştır. İki yılın genel ortalaması olarak yă verimi $40.6 \mathrm{~kg} \mathrm{da}{ }^{-1}$ bulunmuştur (Çizelge 3).

\section{SONUÇ}

Çalışmada, kışlık yetiştirme döneminde ekimi yapılan pelemir denemeleri sonucunda elde edilen varyans analizine göre genotiplerden Karahan ve Populasyon 2 tane ve yağ verimi bakımından öne çıktığ görülmüştür. Yetiştirme dönemi yönünden 2014-2015 kışlık ekim yetiştirme dönemi öne çıkmıştır. Lokasyonlar yönünden ise Ankara (Haymana) lokasyonu her iki yetitirme döneminde de yüksek değerler göstermiştir. Tüm bu veriler değerlendirilerek Karahan genotipinin kışa dayanımının, tane ve yağ veriminin ve yağ oranının yüksek olması nedeniyle kışlık pelemir çeşidi olarak 11.04.2017 tarihinde Tescil Komitesi tarafindan tescil edilerek kayıt altına alınmış ve milli çeşit listesine dahil edilmiştir (TTSM 2017).

\section{KAYNAKLAR}

Altıniğne N, ve Saygın E (1985). Pelemir katımlı unlardan yapılan ekmeklerde bayatlama süresi. Gıda. $5,323-332$.
Arıoğlu H.H, Kolsarıcı Ö, Göksu A.T, Güllüoğlu L, Arslan M, Çalışkan S, Sögüut $T$, Kurt $C$, ve Arslanoğlu F 2010."Yağ Bitkileri Üretiminin Artırılması Olanakları". Türkiye Ziraat Mühendisliği 7. Teknik Kongresi. 11- 15 Ocak. Sayfa : 361- 376. Ankara.

Arslan Y, Subaşı I, Katar D, ve Kodaş R 2012. Farklı Azot ve Fosfor Dozlarının Pelemir Bitkisi (Cephalaria syriaca L.)'nin Verim ve Yağ Oranı Üzerine Etkisinin Belirlenmesi. I. Uluslararası Iğdır Sempozyumu. 19-21 Nisan. Bildiri Özetleri Kitabı, Sayfa:32.

Başar Ş, Karaoğlu M.M, Boz H 2016. The effects of Cephalaria syriaca flour on the quality of sunn pest (Eurygaster integriceps)- damaged wheat. Journal of Food Quality, 39, 13-24. 1472-1477.

Baytop T 1999.“Türkiye'de Bitkiler ile Tedavi”, s:313, İstanbul.

Boz H, ve Karaoğlu M. M (2013). Improving the quality of whole wheat bread by using various plant origin materials. Czech Journal of Food Science. 31(5), 457-466.

Çağlar H 1968."Pelemir”. Güven Matbaası, Ankara.

Çiller M 1977."Pelemir Tohumu Yağı Üzerine Bir Araştırma”.

Hallen E, Ibanoğlu S, and Ainsworth P 2004. Effect of fermented/germinated cowpea flour addition on the rheological and baking properties of wheat flour. J. Food Eng., 63, 177-184.

Karaoğlu M. M 2006.“Cephalaria syriaca addition to wheat flour dough and effect on rheological properties". International Journal of Food Science \& Technology Volume 41, Issue Supplement s2, pages 37-46.

Karaoğlu M. M (2012). Effect of Cephalaria syriaca addition on rheological properties of composite flour. International Agrophysics, 26, 387-393.

Katar D, Arslan Y, Subasi I, ve Kodas R (2012). The effect of different sowing dates on yield and yield components of Cephalaria (Cephalaria syriaca) under Ankara/Turkey ecological condition. Biological Diversity and Conservation, 5(3), 48-53.

TTSM 2017. Tescil Raporları. Arşiv. Tohumluk Tescil ve Sertifikasyon Merkez Müdürlüğü, Ankara.

TTSM 2017. Milli Çeşit Listesi. Tohumluk Tescil ve Sertifikasyon Merkez Müdürlüğü, Ankara.

Yazıcıŏ̆lu T, A. Karaali and J. Gökçen, 1978. "Cephalaria syriaca seed oil". Journal of the American Oil Chemists' Society Volume 55, Number 4, 412-415, DOI: 10.1007/BF02911903.

Yazıcıoğlu T, ve Karaali A 1983. Türk Bitkisel Yağlarının Yağ Asitleri Bileşimleri. Tübitak, Marmara Bilimsel ve Endüstriyel Araştırma Enstitüsü Yayını No 70. 